\title{
Estágio Supervisionado em um Curso de Licenciatura em Educação do Campo: desafios na regência
}

\section{The Challenges found in the supervised internship/regency in a Rural Education Degree Course}

\author{
Alexandre Leite dos Santos Silva (alexandreleite@ufpi.edu.br) \\ Universidade Federal do Piauí, Campus Picos (UFPI) \\ Suzana Gomes Lopes (sglopes@ufpi.edu.br) \\ Universidade Federal do Piauí, Campus Picos (UFPI) \\ Gardner de Andrade Arrais (gardner.arrais@gmail.com) \\ Universidade Federal do Piauí, Campus Picos (UFPI) \\ Tamaris Gimenez Pinheiro (tamarisgimenez@gmail.com) \\ Universidade Federal do Piauí, Campus Picos (UFPI)
}

Resumo: O objetivo deste artigo é apresentar e discutir os resultados de uma pesquisa acerca dos desafios na regência no Estágio Supervisionado em um Curso de Licenciatura em Educação do Campo (LEdoC) com enfoque em Ciências da Natureza da região Nordeste. Para isso, a investigação foi realizada a partir da aplicação de questionários e da análise de documentos. Os resultados mostraram que os principais desafios encontrados na regência no Estágio Supervisionado na LEdoC estudada têm relação com a formação multidisciplinar para o Ensino Médio, que é, devido à composição da estrutura curricular do Projeto Pedagógico do Curso, incongruente com as exigências profissionais e as propostas que conduziram à criação dos cursos por área de conhecimento; com o papel dos Supervisores, no tocante à sua formação/experiência e no que se refere a um efetivo acompanhamento dos estagiários para a formação de educadores do campo; e com as condições materiais das escolas do campo, que não oferecem um espaço adequado para a aprendizagem da docência dentro dos fundamentos da Educação do Campo.

Palavras-chave: Estágio Supervisionado; Educação do Campo; Supervisor de Estágio; Escolas do Campo; Ensino de Ciências.

Abstract: The aim of this paper is to present and discuss the results of a research about the challenges in conducting Supervised Internship in a Rural Education Degree Course (LEdoC), with focus on Natural Sciences from the northeast region. For this, the investigation was performed from the application of questionnaires and the analysis of documents. The results showed that a challenge found in conducting supervised internship/regencyin the LEdoC studied has relation with the multidisciplinary training to high school teaching. The composition of curricular structure of the pedagogical project of course not agree with the professional requirements and the proposals of creation of courses by area of knowledge. The other challenge has relation with the role of supervisors as for their training/experience and about effective monitoring of interns to your training like rural educators. Furthermore, the material conditions of rural 
schools do not offer na adequate space for learning and teaching within the fundaments of Rural Education.

Keywords: Supervised Internship; Rural Education; Internship Supervisor; Rural Schools; Science Teaching.

\title{
1. INTRODUÇÃO
}

O Estágio Supervisionado pode ser definido como

\begin{abstract}
ato educativo escolar supervisionado, desenvolvido no ambiente de trabalho, que visa à preparação para o trabalho produtivo de educandos que estejam frequentando o ensino regular em instituições de educação superior, de educação profissional, de ensino médio, da educação especial e dos anos finais do ensino fundamental, na modalidade profissional da educação de jovens e adultos (BRASIL, 2008a, p. 1).
\end{abstract}

Dessa forma, o Estágio Supervisionado visa aproximar o estudante da realidade profissional que enfrentará, em preparação para o trabalho produtivo, podendo ser nas modalidades obrigatória ou não-obrigatória (BRASIL, 2015). Essa aproximação é realizada mediante o desenvolvimento de atividades pertinentes à formação em um ambiente de trabalho em que o estagiário deve ser efetivamente supervisionado/acompanhado tanto pelo Orientador, que é um professor vinculado à instituição de ensino, como pelo Supervisor, que é um profissional do local de trabalho com formação e/ou experiência na área (BRASIL, 2008a). Nessa direção, o objetivo deste artigo é apresentar e discutir os resultados de uma pesquisa acerca dos desafios na da regência no Estágio Supervisionado em um Curso de Licenciatura em Educação do Campo (LEdoC). Assim, o problema que norteou o trabalho é/foi: quais os desafios encontrados na regência no Estágio Supervisionado em uma LEdoC?

Uma pesquisa booleana por trabalhos em periódicos na área da educação søb com o operador "AND" entre os descritores "Educação do Campo" e "Estágio Supervisionado" não trouxe nenhum resultado na plataforma SciELO (disponível em http://www.scielo.br). A SciELO foi selecionada por se constituir em uma biblioteca eletrônica abrangente, integrada a outras bases de dados, agregando centenas de periódicos provenientes de doze países. No entanto, uma pesquisa com o operador "AND" entre os descritores "Estágio Supervisionado" e "Licenciatura" trouxe 42 resultados. Após a leitura dos títulos e resumos desses artigos foram encontrados seis trabalhos sobre os desafios no Estágio Supervisionado em cursos de licenciatura, como 
Martins (2009), que apontou a falta de condições apropriadas para o Estágio nas escolas públicas e a desmotivação dos supervisores; Rosa, Weigert e Souza (2012), que constataram a discrepância evidente no Estágio Supervisionado entre a formação universitária e as exigências da realidade escolar; Milanesi (2012), que indicou as fragilidades nos papéis dos supervisores, especialmente por contribuírem para manter a dicotomia entre a teoria e a prática; Guerta e Camargo (2015), que perceberam a falta de uma articulação entre a universidade e a escola; Garcia (2016), que expôs o pouco avanço das contribuições do Estágio Supervisionado no cenário das licenciaturas brasileiras, apesar das reformas curriculares, por continuar dicotomizando teoria e prática e pela fragilidade na cooperação entre a universidade e as escolas; e, por fim, Martins et al. (2016), que mostraram, dentre outras coisas, que nem todos os estagiários concebiam o Estágio Supervisionado como um componente curricular importante para a sua formação.

Apesar da existência desses trabalhos, este texto poderá contribuir para a produção acadêmica, especialmente aos estudos na área de formação de professores e ensino de Ciências, pois se propõe a discutir a temática do Estágio Supervisionado em um curso relativamente novo - o Curso de Licenciatura em Educação do Campo (com habilitação em Ciências da Natureza) - e no contexto da Região Nordeste (ASSAI; BROIETTI; ARRUDA, 2018). Dessa forma, similar ao trabalho de Oliveira (2017), este concorrerá para a problematização dos sentidos atribuídos ao Estágio Supervisionado na formação de professores.

Por conseguinte, o texto está organizado da seguinte forma: primeiro, tece algumas considerações sobre a formação de educadores do campo; depois, apresenta o caminho metodológico adotado na pesquisa; em seguida, trata dos resultados e discussões e, depois, faz as considerações finais.

\section{FORMAÇÃO DE EDUCADORES DO CAMPO}

A Educação do Campo refere-se a um paradigma educacional no Brasil (MOLINA; JESUS, 2004), pensada pela população camponesa. O termo emergiu na década de 1990 através, principalmente, do papel do Movimento dos Trabalhadores Rurais Sem Terra - MST (CALDART, 2012; AZEVEDO; AZEVEDO, 2018). Desde 
então, esse paradigma em processo de construção histórica tem tido como fundamentos (i) a superação da dicotomia entre o rural e o urbano, pela sua complementaridade; e (ii) a importância de se criar laços de pertencimento com o campo para o fortalecimento da identidade campesina (BRASIL, 2005). Essa construção também tem recebido a contribuição de diversas matrizes pedagógicas, como a pedagogia do movimento, a pedagogia socialista e a pedagogia do oprimido (CALDART, 2011).

Nessa direção, surgiram desde a década de 2000 as LEdoCs, sob o Programa de Apoio à Formação Superior em Licenciatura em Educação do Campo - PROCAMPO (MOLINA, 2015). Dos mais de 40 cursos existentes atualmente, grande parte possui enfoque na área de Ciências da Natureza, cujo objetivo é formar educadores habilitados para atuarem multidisciplinarmente nessa área de conhecimento no Ensino Fundamental e Médio em escolas do campo. A multidisciplinaridade, nesse caso, pode ser definida como o agrupamento simultâneo de disciplinas sem a exigência de se estabelecer claramente uma interação entre elas (JAPIASSU, 1976). Os egressos desses cursos são também habilitados para a gestão de processos escolares e comunitários (MOLINA, 2015).

De uma forma geral, as LEdoCs são cursos regulares que funcionam em regime de alternância com duas etapas formativas por semestre: o Tempo Universidade, que é quando o aluno tem aulas dentro da universidade, sendo considerada uma etapa presencial; e o Tempo Comunidade, que é quando os estudantes combinam teoria e prática ao desenvolverem pesquisas e/ou mobilizarem a comunidade onde residem ou trabalham (MOLINA, 2015).

Respeitando esse regime formativo, as LEdoCs incluem o Estágio Supervisionado em sua organização curricular, com carga horária de no mínimo 400 horas (BRASIL, 2015). Contudo, como as instituições e cursos detêm relativa autonomia, a maneira como o Estágio Supervisionado é conduzido depende muito dos referenciais teóricometodológicos que o norteiam. Nesse aspecto, a perspectiva do Estágio Supervisionado com pesquisa (PIMENTA; LIMA, 2012) aproxima-se mais das matrizes pedagógicas que formataram as LEdoCs.

A perspectiva da pesquisa (PIMENTA; LIMA, 2012) no Estágio Supervisionado provém dos modelos de professor pesquisador e crítico-transformador, e propõe a 
superação da dicotomia entre a teoria e a prática (STENHOUSE, 1991; GIROUX, 1997). Nessa concepção, o Estágio Supervisionado deve ser, ao mesmo tempo, teoria e prática, ou melhor, espaço que possa conduzir à práxis, pois "o professor é ser da práxis" (PIMENTA, 1997, p. 69). A prática educativa, indissociável da teoria, é considerada na sua dimensão institucional como resultado das ações e do diálogo, em âmbito individual e coletivo, dos atores escolares integrados. Todas as disciplinas do curso devem ser teóricas e práticas e articuladas com o Estágio Supervisionado na formação dos futuros professores. Dessa forma, o Estágio Supervisionado deve propiciar tempos e espaços para a compreensão da realidade escolar através do diálogo, da problematização, da pesquisa e da reflexão crítica (GÜNZEL, 2019).

\section{METODOLOGIA}

Os sujeitos que participaram da pesquisa foram estagiários de turmas de Estágio Supervisionado obrigatório, de uma LEdoC, no ano de 2019, em um município da Região Nordeste. A pesquisa trata-se de um estudo de caso qualitativo, com foco na descrição e interpretação de determinada realidade contextualizada (LÜDKE; ANDRÉ, 2013).

A LEdoC em questão foi criada em 2014 e funciona em regime de alternância, habilitando para a docência multidisciplinar em Ciências da Natureza (Química, Física e Biologia) nas escolas do campo que ofertam o Ensino Fundamental e/ou Médio. O Projeto Pedagógico do Curso, foi reformulado em 2017 e apresenta o componente curricular de Estágio Supervisionado distribuído nos últimos quatro blocos do curso e correspondendo ao Tempo Comunidade: (i) no quinto bloco o Estágio Supervisionado I tem a carga horária de 75 horas e é voltado para a investigação da realidade escolar, principalmente através da observação; (ii) no sexto bloco o Estágio Supervisionado II é de 90 horas e é voltado para a regência em Ciências no Ensino Fundamental; (iii) no sétimo e no oitavo blocos, respectivamente, o Estágio Supervisionado III e o Estágio Supervisionado IV apresentam, cada um, a carga horária de 120 horas e são voltados para a regência em Física, em Química e em Biologia no Ensino Médio.

Esta pesquisa fez um recorte do estudo com turmas de Estágio Supervisionado III e Estágio Supervisionado IV. Nesses componentes, os licenciandos podem escolher a 
escola em que irão estagiar, amiúde a que se localiza em sua comunidade ou próximo dela, de forma a não desconfigurar o propósito da alternância. Também têm a liberdade de escolherem os Supervisores de Estágio, desde que sejam os professores das disciplinas em que farão a regência, seja Física e Biologia (no Estágio Supervisionado III) ou Química e Biologia (no Estágio Supervisionado IV).

Como instrumento de coleta de dados utilizou-se um questionário misto, elaborado conforme Marconi e Lakatos (2003), e encaminhado eletronicamente para 22 estagiários da turma de Estágio Supervisionado III e 16 alunos da turma de Estágio Supervisionado IV, dos quais apenas 23 estagiários responderam. Além de perguntas sobre área de domicílio, faixa etária, sexo, o questionário continha as seguintes questões: (i) Você se considera um sujeito do campo? (Explique a sua resposta); (ii) A escola em que está estagiando é uma escola do campo? (Explique a sua resposta); (iii) Quais as maiores dificuldades que você já enfrentou no Estágio Supervisionado? (iv) Na sua opinião, a regência mais difícil foi em qual componente curricular? (Explique); (v) Qual a formação acadêmica dos seus Supervisores?; (vi) Os seus Supervisores possuem experiência profissional na área do conhecimento que você estagiou?; (vii) Os Supervisores ficaram com você dentro da sala de aula durante a regência?; (viii) De que forma os Supervisores o acompanharam e o apoiaram?; (ix) Na sua opinião, qual deveria ser o papel do Supervisor?

Além das respostas ao questionário, foram analisados documentos, como o Projeto Pedagógico do Curso e relatórios de estágio, consultados no arquivo do Curso. Através desses relatórios buscou-se compreender detalhes acerca das condições materiais de estágio, da formação dos Supervisores e das dificuldades encontradas pelos estagiários.

A análise ocorreu em duas etapas. Primeiramente, houve uma análise estatística, a partir das questões fechadas do questionário. Assim, foi possível obter-se dados sobre as características gerais dos sujeitos, da frequência de suas opiniões quanto a algumas dificuldades enfrentadas no decorrer do Estágio Supervisionado e sobre as suas apreensões quanto aos Supervisores.

Em seguida, foi feita a análise temática, conforme Braun e Clarke (2006). Nessa etapa, a análise consistiu em identificar nas respostas dos estagiários (designados pela 
palavra Estagiário e seguida por um número para preservar o seu anonimato), após uma leitura flutuante, as palavras ou expressões similares que pudessem ser codificadas e aglutinadas em núcleos temáticos. Desse modo, tais núcleos temáticos são o resultado da compilação das respostas fornecidas pelos sujeitos da pesquisa. Todas as respostas de todos os sujeitos participantes foram consideradas, embora na apresentação das sequências discursivas tenha-se optado por aquelas mais representativas.

\section{RESULTADOS E DISCUSSÕES}

Os resultados serão apresentados e discutidos na seguinte sequência: primeiro, serão apresentadas algumas características do grupo de participantes na pesquisa; depois, os desafios principais na regência no Estágio Supervisionado serão expostos em núcleos temáticos.

\subsection{Características dos sujeitos da pesquisa}

A partir dos dados coletados foi possível traçar algumas características sobre os sujeitos: (i) A maioria (74\%) está na faixa etária entre 20 e 30 anos de idade e o restante (26\%) possui acima de 30 anos; (ii) $79 \%$ é do sexo feminino e $21 \%$ do sexo masculino; (iii) $67 \%$ reside na área rural e $33 \%$ na área urbana.

A maioria dos sujeitos (92\%) se considera do campo, conforme algumas explicações selecionadas e apresentadas a seguir:

Considero-me do campo porque aqui nasci e me criei; inclusive estudei no campo até as séries oferecidas naquela época. (Estagiário 7).

Moro em interior onde todos necessitam da agricultura de subsistência para manutenção familiar. Nesse viés acredito ser do campo. (Estagiário 12).

Nasci e cresci no campo. Embora hoje more na cidade, minhas origens são do campo. (Estagiário 14).

Considero-me porque realmente nasci dentro do campo e por vários costumes que aprendi na minha comunidade. (Estagiário 17).

Porque passei toda minha infância no campo, e a maioria das pessoas da minha família vive na zona rural, é um lugar que faz me sentir livre. (Estagiário 19).

Por residir e preservar os costumes campesinos. (Estagiário 20).

Dessa forma, os estagiários manifestaram que se consideram sujeitos do campo por residirem atualmente na área rural ou por outros traços de identidade, como a família, o local onde foram criados, estudaram ou viveram, os costumes e o meio de 
subsistência. Contudo, alguns estagiários (8\%) declararam não se identificar como sujeitos do campo devido ao fato de viverem há muito tempo em áreas urbanas e por não associarem as suas atividades e práticas com o campo.

Grande parte (58\%) dos sujeitos também considerava as escolas em que estagiavam como sendo do campo. Outros (33\%) não consideravam tais escolas como sendo do campo. O restante ( $9 \%$ ) não tinha certeza se estagiava em escolas do campo.

Não diminuindo o valor dos sentidos atribuídos pelos sujeitos sobre a sua identidade e o seu espaço, especialmente quanto a se eles e as escolas em que estagiam são do campo, suas concepções quanto ao que é urbano e ao que é rural sofre ainda a influência das divergências que ocorrem na sociedade e no nível acadêmico (SPOSITO, 2013). É preciso, ainda, evocar que o homem do campo não é definido apenas por sua área de domicílio, mas também por sua cultura, sua formação, sua comunidade, e seu trabalho (KIELING; SILVEIRA, 2015), e que as escolas do campo não são necessariamente as localizadas na área rural, mas aquelas que, mesmo localizadas em áreas ditas urbanas, recebem predominantemente alunos identificados como sujeitos do campo (BRASIL, 2010).

\subsection{Desafios na Regência no Estágio Supervisionado}

A partir da análise foi possível alistar em três núcleos temáticos os desafios enfrentados na regência durante o Estágio Supervisionado na LEdoC: (i) da formação por área de conhecimento, (ii) do papel dos Supervisores e (iii) das condições materiais das escolas do campo.

\subsubsection{Formação para a docência por área de conhecimento}

A formação para a docência por área de conhecimento (Ciências da Natureza) é um desafio que se manifesta no Estágio Supervisionado, durante a regência em Química, Física e Biologia no Ensino Médio. Os estagiários, conforme o Projeto Pedagógico do Curso, fazem nos últimos blocos a regência nessas disciplinas para os quais serão habilitados. Quando questionados sobre as dificuldades enfrentadas no Estágio Supervisionado, a maior parte (54\%) respondeu que tinha dificuldade para ensinar o conteúdo.

Acontece, que esses conteúdos não são contemplados de forma equânime na graduação, sendo $62 \%$ da carga horária de disciplinas obrigatórias em relação ao total 
da carga horária de disciplinas com o conteúdo de Ciências da Natureza composta por conteúdos de Biologia, 20\% de Química, 9\% de Física e 9\% de Geociências (SILVA, 2018).

Além disso, os alunos, em geral provenientes de escolas do campo, experimentaram a precariedade da Educação Básica no meio rural (OLIVEIRA; MONTENEGRO, 2010), o que não lhes assegurou a formação em Ciências necessária para terem o domínio das matérias escolares de Biologia, Física e Química, especialmente para aqueles que cursaram a Educação Básica por meio da modalidade da Educação de Jovens e Adultos (EJA).

A seguinte sequência discursiva ilustra esse desafio:

Pois eram conteúdos que não tinha visto. (Estagiário 3).

Dificuldade com a Física, pois pagamos poucas disciplinas dela. (Estagiário 4).

Porque alguns conteúdos que ministrei em Química, como transformações isobáricas, isotérmicas e isocóricas, não lembro de ter estudado no Ensino Médio. Senti mais dificuldade ainda em falar de Modelos Atômicos; achei complexos e tive que estudar muito. (Estagiário 14).

Está sendo difícil para mim porque conclui meu Ensino Médio de forma acelerada no supletivo, deixando para atrás alguns conteúdos os quais eu preciso rever. Outra questão, é que na Universidade a grade curricular na disciplina de Física é muito pouca e isso acaba prejudicando o futuro docente em sala de aula sobre os conteúdos aplicados. (Estagiário 16).

Os enunciados dos estagiários responsabilizam a deficiência na sua formação básica e superior pela sua dificuldade em ensinar os conteúdos de Ciências da Natureza. Nesse sentido, quanto a quais conteúdos são mais difíceis de ensinar, 50\% expressou ter mais dificuldade com Física, 33\% com Química e 17\% com Biologia.

As complicações no ensino de Biologia foram relacionadas principalmente com a falta de materiais didáticos e a dificuldade de memorizar e explicar nomes e conceitos, enquanto no ensino de Física foram associadas à dificuldade de dominar a linguagem matemática, na forma de cálculos e fórmulas. Quanto à Química, a maioria das respostas associaram a dificuldade em ensiná-la com, segundo o seu ponto de vista, a complexidade dos seus conteúdos.

Essas dificuldades salientaram pelo menos duas fragilidades da formação que está sendo oferecida a esses estagiários: primeiro, quanto à falta de subsídios teórico-práticos na área de conhecimento em que atuam/atuarão; e, segundo, à maneira em que a 
estrutura curricular do curso está construída, dentro de um paradigma cartesiano, fragmentado (MORAES, 2011).

Sobre a primeira fragilidade, referente a uma matriz curricular que carece dos conteúdos específicos de Física e Química em um curso que habilita para o ensino desses componentes no Ensino Fundamental e Médio, foi constatado há décadas, com o trabalho de Shulman (2004) que a falta de domínio da matéria (saber e saber fazer) a ser ensinada pelo professor tem reflexos negativos na sua metodologia de ensino e na gestão da aula/turma (CARVALHO; GIL-PÉREZ, 2011). Molina (2015) indicou que esse poderia ser um risco da formação por área de conhecimento nas LEdoCs:

Um dos maiores riscos dessa estratégia está na precarização da formação docente, que pode ocorrer a partir da supressão de conhecimentos disciplinares fundamentais ao aprendizado de determinados conteúdos, ou mesmo, do acesso a eles de maneira superficial e insuficiente para garantir o seu verdadeiro domínio. (p. 159).

Assim, é preciso que os coletivos da LEdoC criem espaços para a discussão e reflexão em prol da reformulação tanto do PPC como das práticas de ensino, no sentido de que se assegure na formação de educadores do campo a apropriação dos conhecimentos específicos e didático-pedagógicos essenciais para a docência (SAVIANI, 2009).

No tocante à segunda fragilidade, é preciso salientar que a multidisciplinaridade do curso foi intencionada para fomentar a interdisciplinaridade (MOLINA, 2015). No entanto, a análise do PPC do curso revela uma estrutura muito fragmentada de disciplinas relacionadas aos conhecimentos físicos, químicos, biológicos e de outros campos do saber. As ementas das disciplinas dispõem os conteúdos sem incentivar possibilidades de interações entre elas ou entre diferentes especialidades, no sentido da inter e da transdisciplinaridade (JAPIASSU, 2016). Nesse sentido, uma alternativa a ser estudada para o curso seria a organização curricular segundo a abordagem temática e por meio de conceitos unificadores (DELIZOICOV; ANGOTTI; PERNAMBUCO, 2011). É preciso também no Curso um espírito aberto, em nível individual e coletivo, para a pesquisa, para o debate e para a reflexão quanto ao que tem sido produzido em termos de inter e transdisciplinaridade nas LEdoCs e no que é possível ser adotado tendo em vista as especificidades do contexto local, sabendo que a interdisciplinaridade está vinculada à contextualização e que é mais que uma abordagem teórica, mas um 
movimento de atitude e de criação de diálogos e integração entre saberes (ALVES; FALEIRO, 2019).

Problematiza-se também a carga horária destinada para a regência no curso, sendo o total de 240 horas para os componentes de Física, Química e Biologia nos dois últimos períodos. Acontece que essa regência, em cada período, é realizada no prazo de apenas dois meses, correspondentes ao Tempo Comunidade. Então o curto tempo para a concretização da quantidade de horas em regência requerida para os estagiários torna essa tarefa desafiadora. O problema é agravado com o fato de que na região a quantidade de aulas por semana para a área de Ciências da Natureza é relativamente ínfima, sendo duas a três aulas por semana, por turma. Além disso, é comum a carga horária dos professores supervisores ser de apenas 20 horas semanais. Dessa forma, diversos fatores concorrem para dificultar a integralização da carga horária de regência requerida no PPC e em outros documentos normativos institucionais. Essa dificuldade traz à tona a questão sobre quanto tempo seria necessário de prática na formação profissional inicial e, também, como se deveria inclui-la no Estágio Supervisionado, que é um componente teórico-prático (PIMENTA; LIMA, 2012).

\subsubsection{O papel dos Supervisores de estágio}

Por meio da pesquisa foi possível problematizar o papel dos Supervisores de Estágio. Segundo a legislação de estágio (BRASIL, 2008), o Supervisor deve acompanhar o(s) estagiário(s) aos seus cuidados. Para isso, ele deve ter experiência profissional e conhecimento na área de conhecimento do curso do estagiário.

Quanto à experiência profissional, segundo dados obtidos por meio dos estagiários, há professores com 20 anos de docência na área de Ciências da Natureza, enquanto alguns Supervisores estão no primeiro ano de experiência profissional. A partir das respostas, foi verificado que oito Supervisores possuem entre um a cinco anos de docência na área, o que não se constitui ainda um tempo suficiente de experiência, já que não foi ultrapassada nesse lapso temporal a fase de estabilização (TARDIF, 2012).

No aspecto de conhecimento da área, segundo os estagiários, quase todos os Supervisores têm formação acadêmica na área de conhecimento que supervisionaram, seja Biologia ou Química ou Física. Há apenas duas exceções mencionadas: um dos Supervisores de Física é graduado em Matemática e um dos Supervisores de Biologia é 
graduado em Pedagogia. Apenas um dos Supervisores tinha formação em Educação do Campo. Nesse aspecto, a pesquisa teve a limitação de não ter coletado a partir dos próprios Supervisores os dados concernentes à sua formação acadêmica e experiência profissional, o que poderia ter resultado em mais informações pertinentes. Embora os Supervisores tenham formação na área, os relatórios de estágio revelam que as metodologias de ensino deles são marcadas por frequentes aulas expositivas e à base do livro didático (que muitas vezes apenas o professor possui), o que acaba influenciando a prática dos estagiários. Dessa forma, embora os estagiários aprendam, na teoria e na prática na universidade, o valor do ensino não convencional, de formas mais participativas e críticas de ensino-aprendizagem, como o ensino com pesquisa, aulas dialogadas e o trabalho com projetos; terminam se rendendo (conforme mostram os relatórios de estágio) ao ensino tradicional e descontextualizado, dentro de uma concepção bancária de educação (FREIRE, 2013), mantido por seus Supervisores. Assim, nota-se que essa situação cria um bloqueio no diálogo que deveria haver entre o Estágio Supervisionado e outros componentes curriculares do curso e, consequentemente, entre a teoria e a prática (PIMENTA; LIMA, 2012). Com isso, conclui-se que é preciso que se dê atenção fa formação inicial dos professores não apenas ao domínio de conhecimentos específicos na área de Ciências da Natureza, das disciplinas ministradas, mas também ao domínio de conhecimentos didáticopedagógicos (SAVIANI, 2009), e se os Supervisores se constituem em modelos de profissionais na articulação desses conhecimentos.

Problematiza-se também se é preciso, no âmbito das LEdoCs, investigar se os Supervisores possuem formação acadêmica e experiência profissional na área de Ciências da Natureza e/ou em Educação do Campo. Afinal, não se trata de um Curso de Licenciatura em Ciências da Natureza, mas de um Curso de Licenciatura em Educação do Campo. A Educação do Campo, neste curso, refere-se mais que a uma modalidade de ensino, mas a um paradigma educacional (MOLINA; JESUS, 2004) construído sobre princípios (BRASIL, 2005) e referenciais pedagógicos (CALDART, 2011) que devem ter forte impacto filosófico, político e metodológico no ensino (ALENCAR, 2015), no sentido de valorizar e criar diálogos com o espaço campesino e a sua cultura como parte de uma totalidade, o que por sua vez, deveria ser contemplado na formação inicial do educador do campo, inclusive no Estágio Supervisionado. Nesse sentido, uma pesquisa 
relativamente recente com professores de Ciências de escolas do campo em um município do Estado do Piauí mostrou que estavam totalmente alheios aos saberes relacionados com a Educação do Campo (SILVA, 2018), contrariando o disposto na Resolução nº 02, de 28 de abril de 2008 (BRASIL, 2008b), que estabelece diretrizes complementares, normas e princípios para o desenvolvimento de políticas públicas de atendimento da Educação Básica do Campo. Esse documento normativo declara no Artigo $7^{\circ}$, Parágrafo Segundo, sobre a formação dos professores das escolas do campo:

\begin{abstract}
A admissão e a formação inicial e continuada dos professores e do pessoal de magistério de apoio ao trabalho docente deverão considerar sempre a formação pedagógica apropriada à Educação do Campo e às oportunidades de atualização e aperfeiçoamento com os profissionais comprometidos com suas especificidades (BRASIL, 2008b, p. 2).
\end{abstract}

Dessa forma, deveria haver meios de selecionar Supervisores, no âmbito do Estágio Supervisionado para os ledoquianos, que atendam a essas necessidades formativas.

Sobre o acompanhamento dos estagiários, $25 \%$ deles sinalizou que os Supervisores não acompanharam nenhuma de suas aulas, enquanto $46 \%$ afirmou que teve a presença dos Supervisores em algumas das aulas que ministraram durante o Estágio Supervisionado de regência. Outros 25\% afirmou que os Supervisores acompanharam a maioria das suas aulas, enquanto apenas $4 \%$ respondeu que os Supervisores acompanharam todas as suas aulas.

Foi levantado que $13 \%$ dos estagiários declarou não ter tido nenhuma forma de apoio dos seus supervisores. No entanto, a maioria (87\%) dos estagiários afirmou que tiveram de alguma forma apoio dos seus supervisores, na forma de orientações, fornecimento de materiais, dicas sobre como lidar com os alunos, apoio no planejamento das aulas etc. Apesar desse apoio, os estagiários sentiram a necessidade de um acompanhamento mais efetivo, como ilustram as seguintes respostas, ao serem questionados sobre o papel do supervisor de estágio:

Que ele fosse sempre presente, para nos momentos que o estagiário precisasse, ele estivesse ali para ajudar. (Estagiário 7).

Deveria ajudar a gente e não só observar. Deveria fazer intervenções na aula, acrescentar com alguma informação crucial sobre o conteúdo que a gente está explicando. (Estagiário 14). 
Deveria ser um apoio para o estagiário e ensinar como a escola funciona e como é o comportamento dos alunos nas turmas e estar sempre presente na escola quando o estagiário estiver em sala de aula. (Estagiário 18).

Dessa forma, os estagiários expressaram a necessidade de um acompanhamento tanto presencial como através do diálogo, na integração entre a tríade orientadorestagiário-supervisor, considerando que o estágio é também um espaço para a reflexão crítica (PIMENTA; LIMA, 2012). Nesse sentido, a ausência dos supervisores não apenas oblitera as possibilidades da aprendizagem por meio desse diálogo, da socialização profissional, mas também compromete a formação dos licenciandos no sentido atitudinal e ético pois a assiduidade é algo esperado de todo profissional e que deve ser aprendida pelos estagiários em sua imersão no ambiente escolar.

\subsubsection{As condições materiais das escolas do campo}

Outro desafio apontado pelos estagiários foi a infraestrutura das escolas do campo e as condições materiais oferecidas para o trabalho docente nelas. Nesse sentido, a precarização das escolas públicas é um problema que tem sido mais grave no contexto campesino. "Historicamente e de maneira geral, as questões que se colocam sobre a rede de ensino do meio rural referem-se à sua precariedade e insuficiência" (OLIVEIRA; MONTENEGRO, 2010, p. 72).

Nesse âmbito, $21 \%$ dos estagiários citaram a falta de infraestrutura das escolas. Assim, os relatórios de estágio mostram que as escolas sofrem com prédios avariados, banheiros inadequados, bebedouros em más condições de uso, locais com entulhos, falta de climatização nas salas (trata-se de uma região quente no semiárido nordestino), carência de espaços para o armazenamento de materiais específicos (microscópios, terrários, herbários; etc.) e para o desenvolvimento de atividades práticas de Ciências (nenhuma escola possuía um laboratório de Ciências ativo), falta de equipamentos (como projetores, computadores; etc.) e ausência das adaptações necessárias para portadores de necessidades especiais (um dos estagiários é cadeirante). Outros $42 \%$ dos estagiários mencionaram que era difícil durante o estágio lidar com a falta de materiais, como livros didáticos. Alguns estagiários não tinham livros didáticos para si e seus alunos durante a regência. Desse modo, as condições das escolas do campo em que ocorrem o Estágio Supervisionado estão longe do que é esperado pelas diretrizes do Ministério da Educação: 


\begin{abstract}
A Educação do Campo deverá oferecer sempre o indispensável apoio pedagógico aos alunos, incluindo condições infraestruturais adequadas, bem como materiais e livros didáticos, equipamentos, laboratórios, biblioteca e áreas de lazer e desporto, em conformidade com a realidade local e as diversidades dos povos do campo, com atendimento ao art. $5^{\circ}$ das Diretrizes Operacionais para a Educação Básica nas escolas do campo (BRASIL, 2008b, p. 2).
\end{abstract}

Soma-se a isso o problema relacionado ao serviço do transporte escolar, mencionado por $29 \%$ dos estagiários. Esse problema interfere de diversos modos, seja quando há dias em que o transporte não é oferecido e não é possível que os alunos do campo cheguem na escola; seja quando as condições de transporte ou das estradas não são seguras; seja quando os horários de chegada e saída dos veículos chocam-se com os horários das aulas. Além disso, é muito comum o transporte de alunos do campo para a cidade, em vez de deslocá-los do campo para o campo (BRASIL, 2008b).

As condições dos locais em que o Estágio Supervisionado é realizado também devem ser problematizadas, pois segundo a legislação (BRASIL, 2008a), os locais que recebem estagiários devem ofertar instalações que possam proporcionar ao educando atividades de aprendizagem. Contudo, dada à complexidade do problema, visualiza-se que o seu debate e proposições de mudança devem ocorrer em nível coletivo e junto ao movimento por políticas públicas nacionais e locais pelo desenvolvimento das escolas públicas, especialmente no contexto campesino.

\title{
5. CONSIDERAÇÕES FINAIS
}

Os principais desafios encontrados na regência no Estágio Supervisionado na LEdoC estudada têm relação com (i) a formação multidisciplinar para o Ensino Médio, que é, devido à composição da estrutura curricular do PPC, incongruente com as exigências profissionais e as propostas que conduziram à criação dos cursos por área de conhecimento; (ii) com o papel dos Supervisores, no tocante à sua formação/experiência e no que se refere a um efetivo acompanhamento dos estagiários para a formação de educadores do campo; e (iii) com as condições materiais das escolas do campo, que não oferecem um espaço adequado para a aprendizagem da docência dentro dos fundamentos da Educação do Campo.

A pesquisa contribui para as discussões em torno da formação de educadores do campo, sinalizando para um Estágio Supervisionado na perspectiva da pesquisa, que o 
considera como espaço oportuno para o diálogo e a reflexão crítica da realidade escolar, com suas contradições. Como a Educação do Campo, as LEdoCs e seus coletivos docentes e discentes, dado o seu recente ingresso no cenário das licenciaturas, experimentam um período de construção e de amadurecimento. Em nível institucional, estão sendo consolidadas apesar do enfraquecimento das políticas que as fizeram emergir. Assim, é possível, mesmo em um ambiente de incertezas, que no futuro as LEdoCs, seja a partir da pesquisa educacional ou por meio das reivindicações dos movimentos sociais campesinos em seus coletivos, tragam à tona mais problemas e avanços concernentes à formação de educadores do campo, ultrapassando os que estão no bojo deste texto introdutório.

Para o Curso em que a regência no Estágio Supervisionado foi investigada é premente a reformulação do PPC, no sentido de se construir uma estrutura curricular e práticas de ensino que incentivem realmente a inter e a transdisciplinaridade sem, contudo, obliterar os conhecimentos específicos e didático-pedagógicos que devem estar na base da formação inicial dos educadores do campo. Também é importante que considere maneiras de prover, dentro de uma rede de aprendizagem, a melhor integração entre supervisores, orientadores e estagiários e, consequentemente, entre a universidade e as escolas do campo.

Para a instituição em que o Curso está inserido, é imprescindível que continue apoiando com recursos financeiros e logísticos as suas atividades, inclusive o Estágio Supervisionado que ocorre com atividades nas comunidades rurais dos estagiários. Ademais, é preciso que a instituição ofereça tanto debates, bem como mais autonomia, dentro dos limites da legislação educacional, para que a LEdoC possa ter condições para o desenvolvimento do Estágio Supervisionado na perspectiva da pesquisa.

Para os estagiários; a pesquisa aponta para a oportunidade de, diante de um quadro com tantos problemas e incertezas que cercam a sua formação, usarem o Estágio Supervisionado para problematizarem, debaterem, refletirem criticamente e, principalmente, pesquisarem para transformarem coletivamente essa realidade que cerca suas comunidades rurais.

Constatou-se que no âmbito das políticas públicas ainda há muito em que melhorar nas escolas do campo locais, não apenas no quesito infraestrutura, mas 
também no aspecto humano, com professores e gestores que resguardem a ética no ambiente profissional e que compreendam teoricamente, metodologicamente e politicamente o significado de uma Educação no e do campo, dentro de um projeto maior de desenvolvimento para todos.

\section{REFERÊNCIAS}

ALENCAR, M. F. S. Princípios pedagógicos da Educação do Campo: caminho para o fortalecimento da escola do campo. Ciência \& Trópico, Recife, v. 39, n. 2, p. 41-72, 2015 .

ALVES, M. Z.; FALEIRO, W. Interdisciplinaridade na formação de professores em uma LEDOC: desafios de ensinar e aprender. Revista Brasileira de Educação do Campo, Tocantinópolis, v. 4, n. e5368, 2019. DOI:

http://dx.doi.org/10.20873/uft.rbec.e5368.

ASSAI, N. D. S.; BROIETTI, F. C. D.; ARRUDA, S. M. O Estágio Supervisionado na formação inicial de professores: estado da arte das pesquisas nacionais da área de ensino de ciências. Educação em Revista, Belo Horizonte, v. 34, n. e203517, p. 1-44, 2018. DOI: http://dx.doi.org/10.1590/0102-4698203517.

AZEVEDO, M. A.; AZEVEDO, I. R. B. Questão agrária e Educação do Campo: controvérsias e perspectivas. Holos, Natal, v. 1, 237-245, 2018. DOI:

http://doi.org/10.15628/holos.2018.1700.

BRAUN, V.; CLARKE, V. Using thematic analysis in psychology. Qualitative Research in Psychology, v. 3, n. 2, 77-101, 2006.

BRASIL. Ministério da Educação. Grupo Permanente de Trabalho de Educação do Campo. Referências para uma política nacional de Educação do Campo. Caderno de Subsídios, Brasília, DF: 2005.

BRASIL. Ministério da Educação. Lei no . 11.788, de 25 de setembro de 2008. Dispõe sobre o estágio de estudantes. Brasília, DF: 2008a.

BRASIL. Ministério da Educação. Resolução nº 02, de 22 de abril de 2008.

Estabelece diretrizes complementares, normas e princípios para o desenvolvimento de políticas públicas de atendimento da Educação Básica do Campo. Brasília, DF: 2008b.

BRASIL. Decreto Federal $\mathbf{n}^{\mathbf{0}}$ 7.325, de 4 de novembro de 2010. Dispõe sobre a política de educação do campo e o Programa Nacional de Educação na Reforma Agrária - PRONERA. Brasília, DF: 2010.

BRASIL. Ministério da Educação. Resolução $\mathbf{n}^{\mathbf{0}} \mathbf{2}$ de $\mathbf{1}^{\mathbf{0}}$ de julho de 2015. Define as Diretrizes Curriculares Nacionais para a formação inicial em nível superior (cursos de 
licenciatura, cursos de formação pedagógica para graduados e cursos de segunda licenciatura) e para a formação continuada. Brasília, DF: 2015.

CALDART, R. S. Por uma educação do campo: traços de uma identidade em construção. In ARROYO, M. G., CALDART, R. S., MOLINA, M. C. (Orgs.). Por uma educação do campo. Petrópolis, RJ: Vozes, 2011. p. 147-210.

CALDART, R. S. Educação do campo. In CALDART et al. (Orgs.). Dicionário da Educação do Campo. Rio de Janeiro, RJ, São Paulo, SP: Expressão Popular, 2012. p. 257-265.

CARVALHO, A. M. P.; GIL-PÉREZ, D. Formação de professores de ciências: tendências e inovações. 10 ed. São Paulo: Cortez, 2011.

DELIZOICOV, D., ANGOTTI, A. J., PERNAMBUCO, M. M. Ensino de ciências: fundamentos e métodos. 4 ed. São Paulo: Cortez, 2011.

FREIRE, P. Pedagogia do oprimido. 54 ed. Rio de Janeiro: Paz e Terra, 2013.

GARCIA, M. M. A. Políticas curriculares e profissionalização: saberes da prática na formação inicial de professores. Educação em Revista, Belo Horizonte, v. 32, n. 2, p. 131-155, 2016. DOI: http://dx.doi.org/10.1590/0102-4698153483.

GIROUX, H. Os professores como intelectuais: rumo a uma pedagogia crítica da aprendizagem. Tradução de Daniel Bueno. Porto Alegre: Artes Médicas, 1997.

GUERTA, R. S.; CAMARGO, C. C. Comunidade de aprendizagem da docência em estágio curricular obrigatório: aprendizagens evidenciadas pelos licenciandos. Ciência \& Educação, Bauru, v. 21, n. 3, p. 605-621, 2015. DOI:

$\mathrm{http}: / / \mathrm{dx}$.doi.org/10.1590/1516-731320150030006.

GÜNZEL, R. E. Ensinar é aprender: desafios e experiências no estágio de docência.

Revista Insignare Scentia, Chapecó, v. 2, n. 3, p. 222-232, 2019. Disponível em: https://periodicos.uffs.edu.br/index.php/RIS/article/view/11202/7271. Acesso em: 05 out. 2020.

JAPIASSU, H. Interdisciplinaridade e patologia do saber. Rio de Janeiro: Imago Editora, 1976.

JAPIASSU, H. O sonho transdisciplinar. Revista Desafios, Palmas, v. 3, n. 1, p. 3-9, 2016. DOI: http://dx.doi.org/10.20873/uft.2359-3659.2016v3n1p3.

KIELING, R. I., SILVEIRA, R. L. L. O rural, o urbano e o continuum urbano-rural no contexto do desenvolvimento regional. Perspectiva, Florianópolis, v. 39, n. 148, p. 133$143,2015$.

LÜDKE, M., ANDRE M. E.D.A. A Pesquisa em educação: abordagens qualitativas. 2 ed. Rio de Janeiro: E.P.U, 2013. 
MARCONI, M. A.; LAKATOS, E. M. Fundamentos de metodologia científica. 5 ed. São Paulo: Atlas, 2003.

MARTINS, A. F. P. Estágio supervisionado em física: o pulso ainda pulsa... Revista Brasileira de Ensino de Física, São Paulo, v. 31, n. 3, p. 3402.1-7, 2009. DOI: http://dx.doi.org/10.1590/S1806-11172009000300006.

MARTINS, R. R. et al. A importância do Estágio Supervisionado na concepção dos estudantes de ciências biológicas: um estudo com alunos de uma universidade pública de Minas Gerais. Educere et Educare, Cascavel, v. 11, n. 21, p. 177 - 186.

MILANESI, I. Estágio supervisionado: concepções e práticas em ambientes escolares. Educar em Revista, Curitiba, v. 46, p. 209-227, 2012. DOI: http://dx.doi.org/10.1590/S0104-40602012000400015.

MOLINA, M. C., JESUS, S. M. S. A. Contribuições para a construção de um projeto de Educação do Campo. Brasília, DF: Articulação Nacional Por Uma Educação do Campo, 2004.

MOLINA, M. C. Expansão das licenciaturas em Educação do Campo: desafios e potencialidades. Educar em Revista, Curitiba, v. 55, p. 145-166, 2015 DOI: http://dx.doi.org/10.1590/0104-4060.39849.

MORAES, M. C. O paradigma educacional emergente. Campinas, SP: Papirus, 2011.

OLIVEIRA, L. L. N. A., MONTENEGRO, J. L. A. Panorama da educação do campo. In MUNARIM, A. et al. (Orgs.). Educação do campo: reflexões e perspectivas. Florianópolis: Insular, 2010. p. 47-80.

OLIVEIRA, M. B. O estágio curricular na formação de professores: revisitando o debate. Holos, Natal, v. 3, p. 41-50, 2017. DOI:

https://doi.org/10.15628/holos.2017.5760

PIMENTA, S. G. O estágio na formação de professores: unidade teoria e prática? São Paulo: Cortez, 1997.

PIMENTA, S. G., LIMA, M. S. L. Estágio e docência. São Paulo: Cortez, 2012.

ROSA, J. K. L., WEIGERT, C., SOUZA, A. C. G. A. Formação docente: reflexões sobre o estágio curricular. Ciência \& Educação, Bauru, v. 18, n. 3, p. 675-688, 2012. DOI: http://dx.doi.org/10.1590/S1516-73132012000300012.

SAVIANI, D. Formação de professores: aspectos históricos e teóricos do problema no contexto brasileiro. Revista Brasileira de Educação, Rio de Janeiro, v. 14, n. 40, p. 143-155, 2009. DOI: http://dx.doi.org/10.1590/S1413-24782009000100012.

SHULMAN, L. S. The wisdom of practice: essays on teaching, learning, and learning to teach. San Francisco, USA: Wiley Imprint, 2004. 
SILVA, A. L. S. Necessidades formativas de professores de ciências de escolas do campo: um estudo no semiárido piauiense. 2018. Tese (Doutorado em Educação) Universidade Federal de Uberlândia, Uberlândia, Minas Gerais, Brasil, 2018.

SPOSITO, M. E. B. S. A questão cidade-campo: perspectivas a partir da cidade. In SPOSITO, M. E. B., WHITACKER, A. M. (Orgs.) Cidade e Campo - Relações e Contradições e entre o urbano e rural. São Paulo: Outras Expressões, 2013. p. 111-130.

STENHOUSE, L. Investigación y desarrollo del curriculum. España: Ediciones Morata, 1991.

TARDIF, M. Saberes docentes e formação profissional. 14 ed. Rio de Janeiro: Vozes, 2012.

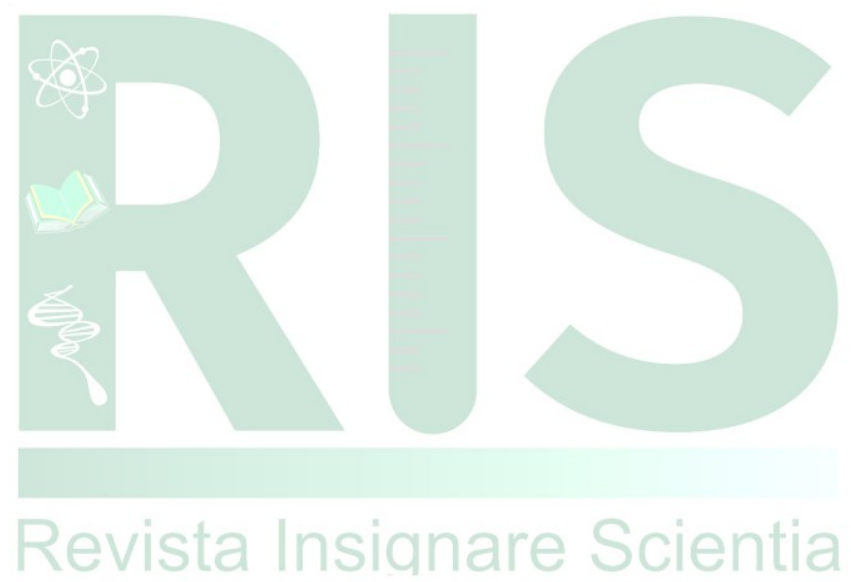

